\title{
An Investigation into the Association between Personal Skills, Organizational Learning, and Innovation, and Organizational Performance in the Power Distribution Company, Northern Kerman
}

\author{
Ayyub Sheikhy 1 \\ ${ }^{1}$ Management Department, Rafsanjan Branch, Islamic Azad University, Rafsanjan, Iran \\ Azam Shafiee ${ }^{2}$ \\ ${ }^{2}$ Department of Management, Kerman Branch, Islamic Azad University, Kerman, Iran
}

\section{Doi:10.5901/mjss.2015.v6n6s2p715}

\section{Abstract}

The performance of an organization and its members depends on many factors including personal skills, organizational learning and innovation. Many of these factors may be related to each other and directly and indirectly affect the organizational performance. This paper, thus, aims to study how personal skills, organizational learning and innovation are associated with the organizational performance in the Power Distribution Company in Northern Kerman. This is a correlational research study with information gathered by a sample of 80 employees from the Power Distribution Company in Northern Kerman. Data were gathered by structural equations to test the relation between these four factors. According to results, personal skill was founded to be positively linked with organizational performance.

Keywords: Personal Skills, Organizational Learning, Organizational Performance

\section{Introduction}

The life of any organization mostly relies on their dynamic interaction with internal and external environment. Such interaction helps organizations collect the latest information and sciences and make the required changes in their organizational performance and behavior. Accordingly, the organization has to acquire sufficient resources and meet the environment true demands.

Employees' skills and awareness, also, make a valuable contribution to the organizations' life. The more updated such contexts, the higher the compatibility with the current varying environment would be. This, on the one hand, leads individuals to create knowledge and skills specified to employees, and on the other hand, to contribute to the improvement of organizational efficiency and effectiveness and adapt to the varying environment pressures (Li, 2001, 44).

Planning for training to improve people's learning and personal skills encompasses some purposes including the improvement of knowledge, information, skills and capabilities. This also prepares employees for implementing their new tasks and accepting higher responsibilities. Training and developing human resource may create employees equipped with deeper insight, higher knowledge and wisdom and more skills and capabilities to do their occupational tasks and responsibilities and may realize organizational objectives more efficiently and effectively (Seyf, 1992, 65). This research is important as to the fact that the importance of theoretical discussion on the organizational performance, especially in small and medium-sized industries, is often ignored. This research, thus, studies the effect of personal skills on the organizational performance by innovation in the Power Distribution Company, Northern Kerman.

\section{Research Literature}

Technological revolutions have made deep changes in jobs. Therefore, it is critically necessary for employees to improve their personal skills. Modern societies demand developed people being able to optimally fulfill their occupational missions and realize organizational objective relying on their insight and skills. Those countries failing to develop their people's skills and knowledge and more effectively take advantage of it for the national economy cannot develop in any other area. The organizations' survival highly depends on their employees' skills, awareness, and knowledge. The higher trained the 
people, the better they would improve the organizational efficiency. The organizations' growth, survival and adaptability virtually rely on the development of employees (Rahnavard, 1969, 43).

Koln (1999) examined how personal skills and organizational learning were linked. Flud (1998) studied how much and how systemic thinking affected personal skills and built up learning motivation. Thomas (1994) measured the association between personal skills and learning (Kang, 2007, 238). He argued that organizational learning was induced by personal skill and both required managers' concentration on the systemic thinking. This finally results in improved performance (Ibid, 240). Leonard (1992) showed the personal growth in learning laboratories. Kavilson analyzed learning in SMEs. Horlie and Hourt (1998) found a positive link between innovation and organizational learning. Finally, Hanavanisch (2002) revealed the negative impact of ignoring the importance of innovation on the organizational performance (Hanvanischet al.2006, 604).

Garcia Moralesa (2007) examined personal skills and analyzed its relation with learning and innovation. The main purpose of training resulting in learning is to change employees' behavior in practice. Making change improves skills and increase people's knowledge. If they can effectively and efficiently carry out their current job, they will be well-prepared to improve their position with higher responsibility. Organizations' effectiveness requires employees with improved personal skills (Garcia-Moralesa, 2007, 56).

Training and developing human resource may create employees equipped with deeper insight, higher knowledge and wisdom and more skills and capabilities to do their occupational tasks and responsibilities and may realize organizational objectives more efficiently and effectively. Training may raise people's skills and knowledge and alter their insight and social behavior. It also affects what employees know, how they perform their tasks and their perception of their job (Tsang, 1997, 59).

George Straus and Leonard Sils argued that efficiency directly depended on the method of training employees. In terms of training and efficiency, Marr defines it as producing abilities to create more efficient jobs and acquiring better conditions to achieve a higher position (Marr, 2003, 682).

Garvin (2006) believed that the managers had identified the clear link between training and employees' efficiency. The outstanding changes in industrial tools and equipment and modern techniques for increasing production encourage managers to struggle for finding suitable solutions for improving organizational efficiency. Such solutions are applicable by continuous and broad in-service training. It is necessary to apply new methods which make using new instruments possible and inspire employees to take the required steps toward the realization of organizational objective (Garvin, 2000, $61)$.

- Personal Skills: refer to the capacity to grow and learn at a personal level emphasizing on learning aspects belonging to the person. The organization's survival highly depends on skills, awareness and knowledge. The higher trained the people, the better they would improve the organizational efficiency. Those equipped with improved skills by training may better adapt themselves to varying environmental pressures. The organizations' growth, survival and adaptability virtually rely on the development of employees (Rahnavard, 2005, 44).

- Learning: there is now a new perception of learning differing from its concept raised in administrative and organizational theories of several decades ago. As to the complicated nature of today's issues including technological advancements, unsustainable environment and changing individual and group values, the focal emphasis has shifted towarda new process of distributing and communicating information and knowledge about social and organizational issues so that it would be possible to make more practical approaches for addressing these subjects and help the receivers of information engage in all stages of developing and implementing policies (Bernolak, 1997, 205).

Regarding the current social needs encompassing stability and variation both in terms of environmental conditions and personal expectations, some techniques such as learning system suggest more practical approaches to face social and organizational problems.

Learning system has some features creating new approaches to implement a participation system for finding solution for complicated social and administrative issues in revolving societies. As a new paradigm of management, this system has appeared both generally in the whole society in terms of developing and enforcing policies and in a limited manner on the ground of solving practical and influencing subjects. Such new approach can be a response to organizational problems in current unsustainable environment with all variables including values and expectations are being revolved (Ibid, 206). Organizational learning has now drawn the attention and interest of organizations searching for improved competitive advantages, innovation, and effectiveness. Argyris and Schon (1995) define organizational learning as "discovering and modifying mistakes". In another definition by George Huber, learning can be applied to any level of analysis for a person, group or organization. According to Huber, an identity learns when changes its potential 
behavior by processing information.

Tsang (1997) argued that two terms "organizational learning" and "learning organization" are sometimes applied mistakenly. He considers organizational learning as a concept to describe especial types of organizational activities. Learning organization though refers to a particular type of organization. Since the onset of the third millennium, along with studies conducted on world known universities on revising the structure and role of biotechnology organizations, managers' thoughts have also changed in large companies (Tsang, 1997, 57). Such scientific structure revision of "learning organization" was first called in the Journal of Massachusett Technology as "organizational revolution". According to Peter Sange (2004), mental model is an effective rule for the learning organization stressing on human beings' limitations and inabilities (i.e. inability to think, rethink and learning) to progress the process of changing self and the organization. It also searches for methods of revising mental models and explaining their role in practical rethinking. He called such revolution as "time-oriented learning" (Sange, 2005, 93).

Innovation is putting new thoughts and insights deriving from creativity into practice. Stephen P. Robins regards innovation as a process of making a creative approach and converting it into a new product, service and operation method. Therefore, innovation is a sort of change; any change though cannot be called innovation. Innovation is a novel change created based on new insights that have not existed before. Hence, innovation is a sort of change; any change though cannot be called innovation. Many studies have shown that the ability to create new idea or innovation is relatively general among all human beings. Analyzing psychological tests also discloses that creativity has been normally divided. However, the effectiveness of creativity is more related to efforts and perseverance than to inner talent. Some believe that the best ideas are often raised by those who are not professional in their fields (Coveyr, 1990, 120).

When an organization lacks of creativity, it has nothing to do with employees' talent or capacity, personality and mental structure. This can be attributed to the approaches of development and training sections. Creativity is, in fact, the appearance of a new thought. But, innovation means putting that thought into practice.

- Evaluating performance: it is abroad subject affected by a wide range of fields and scholars. Many new reports, articles and software have been developed in this regard (Neely, 2003, 57).

\section{Research Model}

Our research model is based on literature review, especially on a study conducted on the Spanish organizations by Garcia Moralesa $(2007,56)$.

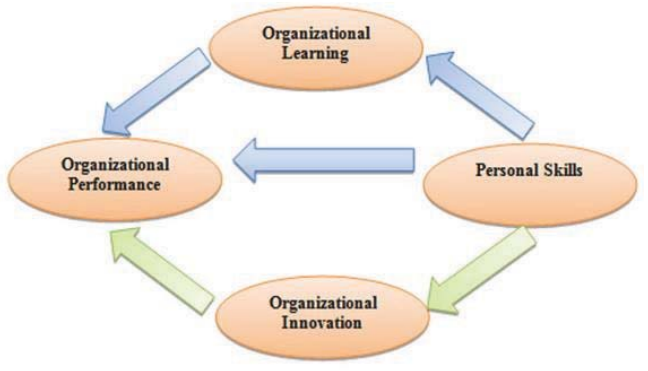

Figure 1. Research analysis model

\section{Research Hypotheses}

First Hypothesis: organizational learning plays a mediating role between personal skills and organizational performance. Second Hypothesis: organizational innovation plays a mediating role between personal skills and organizational performance.

\section{Research Methodology}

This is a causal descriptive research study examining the relationship between variables and the extent of such impact. Considering all possible associations between variables, the presence or the absence of such links was investigated 
using the structural equation model.

The statistical population included the employees working for Power Distribution Company, Northern Kerman. The research raised three leading hypotheses analyzed by LISREL 8.8.

\section{Structural Equation Modeling}

As a strong and holistic multivariate regression analysis technique, the structural equation modeling allows researchers to test simultaneously a set of regression equations. This is a comprehensive statistical approach for testing hypotheses on the association between observed and latent variabes (Human Heydarali, 2008).

There are a number of tests and indexes, called fitting indexes, to assess the structural equation model. They are constantly being compared, developed and revolved. There is no common consent though even on a single optimal test.

Here, several indexes were employed including:

Relative Chi Square (x2/df) - is one of the general indexes to consider free parameters in fit index calculation. Chi square is a ratio estimated by dividing the chi square by the model degree of freedom. The acceptable value is between 1 and 3 (Human, 2008).

RMSEA - it is reported decimally and calculated for different confidence intervals. It is smaller than 0.1 in acceptable models andthe fitness of models with values greater than 0.1 is weak.

Goodness-of-fit index (GFI): it calculates the sum squares, explained by model, to the total sum squares of the estimated matrix. The changes range from zero to 1 . The acceptable value should be greater than 0.9 .

Normed Fit Index (NFI) - is one of the comparative indexes. NFI is based on the variables available in the model, as their high correlation coefficients result in high values of comparative fit indexes. The acceptable value should be greater than 0.9 .

Note, also, that t-value is used to study the model significance. This means that if t-value is greater than 1.96 or smaller than -1.96, it would be significant at the confidence level of $95 \%$.

Root Mean Square Residual (RMR) - it is a criterion for measuring the average of residuals. In a model with an acceptable goodness of fit, the residuals are very small. To sum up, the closer the criterion to the zero, the better the model goodness of fit would be.

Evaluating the data fitting is the most important stage of statistical analysis for which the confirmatory factor analysis 4 is employed.

\section{Confirmatory Factor Analysis (Measurement Model)}

Confirmatory factor analysis is adopted to assess how reliable and valid the measurement scale is (Human, 2008, 17). It studies this question that if the selected questions provide suitable factor structures form measuring the research dimensions.

The following table presents the confirmatory factor analysis.

Table 1: Confirmatory factor analysis results

\begin{tabular}{|l|l|c|c|c|}
\hline Indexes & Sub-indexes & Factor Load & T & SE \\
\hline \multirow{3}{*}{ Organizational Performance } & Environment & 0.65 & 6.58 & 0.10 \\
\cline { 2 - 5 } & Leadership Style & 0.78 & 5.88 & 0.13 \\
\hline Individual Skills & Technical & 0.41 & 3.86 & 0.11 \\
\cline { 2 - 5 } & Human & 0.47 & 3.44 & 0.14 \\
\cline { 2 - 5 } & Conceptual & 0.53 & 4.67 & 0.11 \\
\hline \multirow{5}{*}{ Organizational Learning } & Individual Skills & 0.77 & 6.68 & 0.12 \\
\cline { 2 - 5 } & Mental Models & 0.56 & 7.31 & 0.08 \\
\cline { 2 - 5 } & Common Perspective & 0.48 & 5.32 & 0.09 \\
\cline { 2 - 5 } & Team Learning & 0.66 & 5.28 & 0.13 \\
\cline { 2 - 5 } & Systemic Thinking & 0.71 & 8.38 & 0.08 \\
\hline Organizational Innovation & Environment & 0.71 & 8.38 & 0.08 \\
\cline { 2 - 5 } & Personal Motivation & 0.67 & 10.31 & 0.06 \\
\cline { 2 - 5 } & Personality & 0.44 & 11.23 & 0.04 \\
\cline { 2 - 5 } & Problem-solving & 0.56 & 12.66 & 0.04 \\
\cline { 2 - 5 } & Mental Power & 0.52 & 8.38 & 0.06 \\
\hline
\end{tabular}


According to above table, t statistic is greater than 1.96 in all cases. It is, thus, concluded that the selected questions provide suitable factor structures for measuring studied dimensions in the research model.

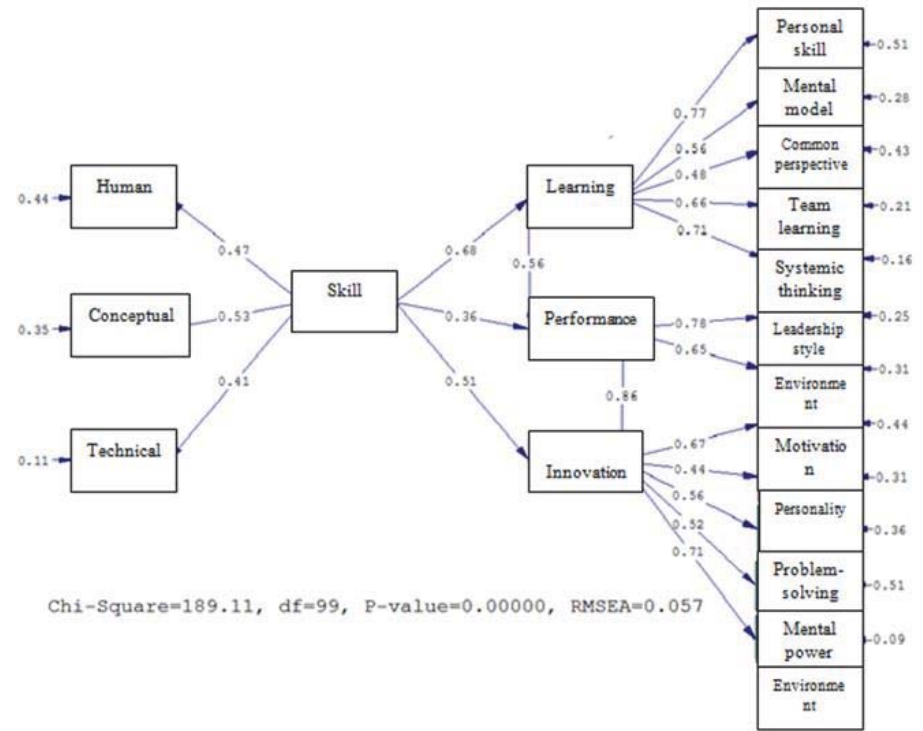

Figure 1. Factor coefficients and the coefficient of the research model route

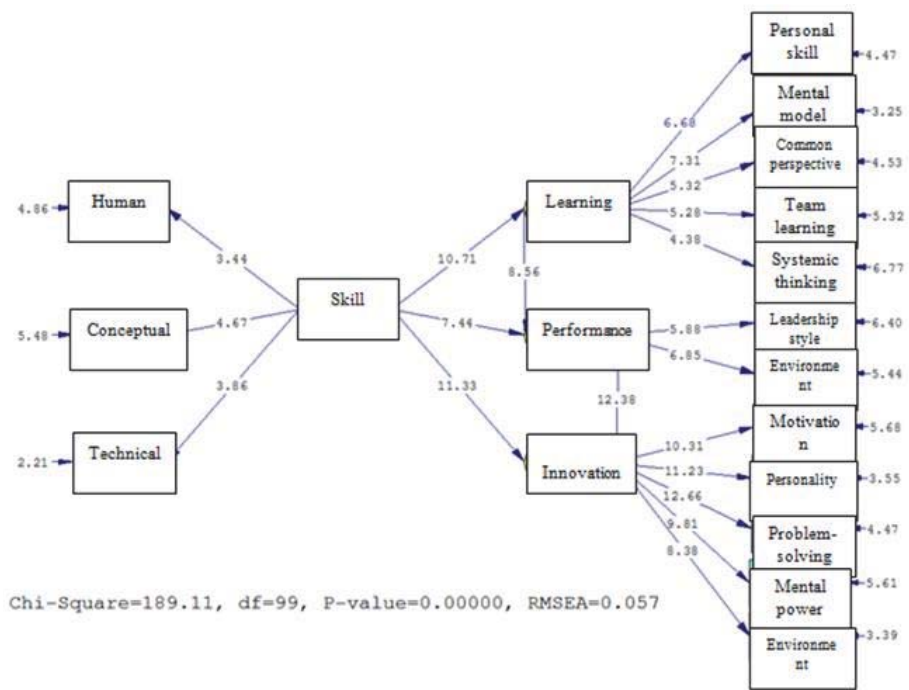

Figure 2. t-test results for the first research model

\section{Model Fitting}

Fitting shows how much a model matches data. In structural equations analysis, following the estimation of parameters and before interpreting them, the model fitting should be ascertained. The following table studies fitting indexes. 
Table 2: Fitting indexes

\begin{tabular}{|c|l|c|c|}
\hline Test & Description & Acceptable Values & Obtained Values \\
\hline X2/df & Relative chi square & $<3$ & 1.91 \\
\hline RMSEA & Root Mean Square Error of Approximation & $<0.1$ & 0.057 \\
\hline GFI & Goodness-of-fit index & $>0.9$ & 0.94 \\
\hline RMR & Root Mean Square Residual & $<0.1$ & 0.051 \\
\hline NFI & Normed Fit Index & $>0.9$ & 0.93 \\
\hline CFI & Comparative Fit Index & $>0.9$ & 0.97 \\
\hline
\end{tabular}

Regarding the above table, MSEA is 0.057 and smaller than 0.1. This shows that the mean square of model errors is good and the model is acceptable. The chi square value is between 1 and 3 and the values for GFI, CFI, and NFI were estimated at greater than 0.9. This validated the measurement model. As the questionnaire and model fitting were confirmed as valid, next section studies the test and hypotheses using confirmed dimensions.

\section{Conclusion and Suggestions}

First Hypothesis studies the mediating role of organizational learning in the relationship between individual skills and the organizational performance. Put it differently, the indirect link of the impact of personal skill on the organizational performance was examined.

To study the indirect effects of the independent variable on dependent variable, the following requirements should be met. Firstly, the association between the independent and mediating variables should be proved to be significant. The same is also true of the mediating and dependent variables. In case the above requirements are met, a significant indirect association will be found. The route coefficient is then obtained by multiplying the relationship between the independent and mediating variables by the association between the dependent and mediating variables. Given diagrams 1 and 2, the route coefficient of personal skill and organizational learning is obtained at 0.68 which is a positive value. The t-value is 10.71 which is greater than 1.96. At a confidence level of 95 percent, it can be concluded that personal skills are significantly associated with organizational learning. The route coefficient of organizational learning and organizational performance is 0.56 and the t-statistic is 8.56 , which is greater than 1.96. Therefore, it has a significant effect at the confidence level of 95 percent. The route coefficient of the indirect effect of personal skills on the organizational performance is $0.56 \times 0.68=0.38$. The first hypothesis is, thus, verified.

Second Hypothesis studies the mediating role of organizational innovation in the relationship between individual skills and the organizational performance. Put it differently, the indirect link of the impact of personal skill on the organizational performance was examined.

Given diagrams 1 and 2, the route coefficient of personal skills and organizational innovation is obtained at 0.51 which is a positive value. The t-value is 11.33 which is greater than 1.96. At a confidence level of 95 percent, it can be concluded that personal skills are significantly associated with organizational innovation. The route coefficient of organizational innovation and organizational performance is 0.86 and the t-statistic is 12.38 , which is greater than 1.96. Therefore, it has a significant effect at the confidence level of 95 percent. The route coefficient of the indirect effect of personal skills on the organizational performance is $0.86 \times 0.51=0.44$. The second hypothesis is, thus, verified.

On the other hand, regarding diagrams 1 and 2, the route coefficient of personal skills and organizational innovation is obtained at 0.36 which is a positive value. The t-value is 7.44 which is greater than 1.96 . At a confidence level of 95 percent, it can be concluded that personal skills are significantly associated with organizational innovation. According to results, the effect of personal skills on organizational performance through innovation is more than its effect through learning.

\section{Suggestions}

Bigger samples are recommended to be studied in future in other sections. In future studies, the effects of other variables should be examined in lower levels. It is also suggested to study those factors eliminating the association between personal skills, organizational innovation, and learning and performance. 


\section{References}

Argyris, C. and schon, D., 1996, Organisational learning II: theory, method and practing, Reading, Mass: Addison Wesley.

Bernolak, I.,1997, "Effective Measurement and successful Elements of company productivity : the basis of competitiveness and world prosperity", International journal of Production Economics, vol. 52.

Garvin,d,a,2000,Learning in Action,A guide to putting the Learning organization to work,Bostenon,Mass:Harvard Business School press.

Chin, W. W. (2003). Issues and opinions on structural equation modeling. MIS

Cover.stephen, 1990, "the seven habits of highly Effective people", Simon Schuster INC.U.S.A.FE.

Cronbach,L.j.(1951).coefficient alpha and the internal structure of test . Psychometrika. 16(3). 297-334

Hanvaisch,S.,Sivakumar,k., Tomas,G.,2006, The relation of learning \& memory with Orgazinationalperformance,Journal of the academy of marketing science,vol,34 No.4.

Human, H., (2001), analyzing multivariate data in behavioral research, cultural messenger, Tehran, first edition

Human, H.A. (2008), structural equation modeling using LISREL, Organization for Study and Compilation of Human Sciences Book in Universities, Tehran

Kang,S.c,Morris,s.S, and Snell ,S.A.,2007,Relational Archetypes, Orgazinational Learning \&value creation ,Academy of Management review,vol.32 No.1.

Kaplan,R.s.And Norton,d.p.,1992,The balanced scorecard:Measures that Drive Performance,Harvard Business Review,JanuaryFebruary.

Li,p.,2001,Design of performance Measurmentsystems:a stakeholder Analysis Framework,The Academy of Management Review Mississippi State,April.

Marr,B.\&Neely,A.,2001,Measuring E-business performance ,Twelfth Annaual Conference of the Production \&Operations Management Society ,Orlando FI.

Marr,B.\&Schiuma,G,.2003,Business performance Measurment :past,present\&future,Management Decision41/8.

Medori, D.\&Steeple, D, A Framework for Auditing \& Enhancing performance Measurmentsystems,International journal of Operations \&Production Management,vol $20 \mathrm{No5}$.

Neely .A.\& Adams,C.,2002, Perspectives on performance: The performance prism, forthcoming in journal of cost management.

Neely, A.D., Richards, A.H., Mills, J.F.,Platts, K.W., Bourne, M.C.S., Gregory, M.\& Kennerley, M., 2000, performance measurement system Design :Developing \& testing a process-based Approach,International journal of operations \& production Management ,vol.20 NO.10.

Rahnavard, F.A. (1999), organizational learning and learning organization, Journal of Public Management, Public Management Education Center Press, 43

Sange, P., Kliyner, A., Raports, SH., Ross, R., Root, G., Smith, B., (1994), Dancing change, Hussein Akbari, MasoudSoltani, Ariana Industrial Research Group

Seyf, A., (1996), methods for educational measurement and appraisal, Duran Press, Tehran, first edition

Senge.P.M.,1990,The Fifth Discipline :The Art \& practice of the Learning organization ,Century Business,London.

Tsang,E.,1997.Organizational learning \& the learning organization:a dichotomy between descriptive \& prescriptive research,Human Relations,50,1. 